\title{
Typical Imaging Patterns in COVID-19 Infections of the Lung on Plain Chest Radiographs to Aid Early Triage
}

\section{Typische Befundmuster bei COVID-19-Infektionen der Lunge auf Röntgenaufnahmen des Thorax zur Unterstützung einer frühen Triage}

Authors

Judith Kasper ${ }^{1}$, Josua Decker ${ }^{1}$, Katharina Wiesenreiter ${ }^{1}$, Christoph Römmele², Alanna Ebigbo², Georg Braun², Thomas Häckel ${ }^{1}$, Florian Schwarz' ${ }^{1}$ Markus Wehler ${ }^{3}$, Helmut Messmann², Thomas J. Kröncke1 ${ }^{1}$, Christian Scheurig-Münkler ${ }^{1}$

Affiliations

1 Department of Diagnostic and Interventional Radiology and Neuroradiology, University Hospital Augsburg, Germany

2 Department of Gastroenterology, University Hospital Augsburg, Germany

3 Department of Emergency Medicine and Department of Medicine IV, University Hospital Augsburg, Germany

Key words

COVID-19, chest X-ray, viral pneumonia

received 29.10 .2020

accepted 01.02.2021

published online 10.03.2020

Bibliography

Fortschr Röntgenstr 2021; 193: 1189-1196

DOI 10.1055/a-1388-8147

ISSN 1438-9029

(C) 2021. Thieme. All rights reserved.

Georg Thieme Verlag KG, Rüdigerstraße 14,

70469 Stuttgart, Germany

Correspondence

Dr. Judith Kasper

Department of Diagnostic and Interventional Radiology and Neuroradiology, University Hospital Augsburg, Stenglinstraße 2, 86156 Augsburg, Germany

Tel.: $+49 / 821 / 4002441$

judith.kasper@uk-augsburg.de

\section{ZUSAMMENFASSUNG}

Hintergrund Bewertung der Befundmuster einer pulmonalen COVID-19-Infektion im Thorax-Röntgen und ihres Werts bei der Abgrenzung zu anderen viralen Pneumonien.

Material und Methoden Alle Patienten, die sich zwischen dem 3. Februar und dem 8. Mai 2020 mit Atemnot vorstellten und bei denen der Verdacht auf eine COVID-19-Infektion bestand, wurden, sofern eine Thorax-Röntgenaufnahme durchgeführt wurde, in diese Analyse einbezogen $(n=321)$.
Die bildgebenden Befunde wurden als typisch für COVID-19 (bilaterale, periphere Verschattungen/Konsolidierungen), nicht typisch (Befund passend zur Lobärpneumonie), unbestimmt (alle anderen Verteilungsmuster von Infiltraten) oder keine (keine Infiltrate) klassifiziert. Zur Beurteilung des diagnostischen Werts der Kategorie "typisch" wurden Sensitivität, Spezifität sowie positiver und negativer prädiktiver Wert bestimmt. Der Chi-Quadrat-Test wurde verwendet, um die Musterverteilung zwischen den verschiedenen Arten von Pneumonien zu vergleichen.

Ergebnisse Infiltratmuster, die als typisch für eine COVID-19Infektion definiert wurden, wurden bei 35/111 (31,5\%) Patienten mit bestätigter COVID-19-Infektion dokumentiert, aber nur bei 4/210 (2\%) Patienten mit irgendeiner anderen Art von Lungenentzündung, was zu einer Sensitivität von $31,5 \%$, einer Spezifität von $98,1 \%$ sowie einem positiven und negativen prädiktiven Wert von $89,7 \%$ bzw. 73 \% führte. Die Sensitivität konnte auf $45,9 \%$ erhöht werden, wenn auch unilaterale, periphere Verschattungen/Konsolidierungen ohne relevante Pathologie kontralateral als typisch für eine COVID-19-Infektion berücksichtigt wurden. Dabei nahm die Spezifität nur geringfügig auf 93,3\% ab. Die Verteilung der Infiltratmuster auf die benannten Kategorien zwischen COVID-19-Patienten und Patienten mit sonstigen Arten von Lungenentzündungen unterschied sich signifikant $(p<0,0001)$.

Schlussfolgerung Die moderate Sensitivität erlaubt zwar nicht den sinnvollen Einsatz des Röntgen-Thorax im Rahmen des primären Screenings, das spezifische Befundmuster in einem relevanten Anteil der Betroffenen sollte jedoch als zusätzliche Information rasch kommuniziert werden und entsprechende Schutzmaßnahmen triggern.

\section{Kernaussagen:}

- COVID-19-Infektionen zeigen bei 1/3 der Patienten spezifische Infiltratmuster im Röntgenbild.

- Bilaterale, periphere Verschattungen und/oder Konsolidierungen sind typische Infiltratmuster.

- Unilaterale, periphere Verschattungen und/oder Konsolidierungen sollten ebenso den Verdacht auf eine COVID-19Infektion wecken. 


\section{ABSTRACT}

Purpose To evaluate imaging patterns of a COVID-19 infection of the lungs on chest radiographs and their value in discriminating this infection from other viral pneumonias.

Materials and Methods All 321 patients who presented with respiratory impairment suspicious for COVID-19 infection between February 3 and May 8, 2020 and who received a chest radiograph were included in this analysis. Imaging findings were classified as typical for COVID-19 (bilateral, peripheral opacifications/consolidations), non-typical (findings consistent with lobar pneumonia), indeterminate (all other distribution patterns of opacifications/consolidations), or none (no opacifications/consolidations). The sensitivity, specificity, as well as positive and negative predictive value for the diagnostic value of the category "typical" were determined. Chi test was used to compare the pattern distribution between the different types of pneumonia.

Results Imaging patterns defined as typical for COVID-19 infections were documented in 35/111 (31.5\%) patients with confirmed COVID-19 infection but only in 4/210 (2\%) patients with any other kind of pneumonia, resulting in a sensitivity of $31.5 \%$, a specificity of $98.1 \%$, and a positive and negative predictive value of $89.7 \%$ or $73 \%$, respectively. The sensitivity could be increased to $45.9 \%$ when defining also unilateral, peripheral opacifications/consolidations with no relevant pathology contralaterally as consistent with a COVID-19 infection, while the specificity decreases slightly to $93.3 \%$. The pattern distribution between COVID-19 patients and those with other types of pneumonia differed significantly $(p<0.0001)$. Conclusion Although the moderate sensitivity does not allow the meaningful use of chest radiographs as part of primary screening, the specific pattern of findings in a relevant proportion of those affected should be communicated quickly as additional information and trigger appropriate protective measures.

\section{Key Points:}

- COVID-19 infections show specific X-ray image patterns in $1 / 3$ of patients.

- Bilateral, peripheral opacities and/or consolidations are typical imaging patterns.

- Unilateral, peripheral opacities and/or consolidations should also raise suspicion of COVID-19 infection.

\section{Citation Format}

- Kasper J, Decker J, Wiesenreiter K et al. Typical Imaging Patterns in COVID-19 Infections of the Lung on Plain Chest Radiographs to Aid Early Triage. Fortschr Röntgenstr 2021; 193: 1189-1196

\section{Introduction}

In December 2019, the novel severe acute respiratory syndrome coronavirus 2 (SARS-CoV-2) first appeared in Wuhan, China. It primarily affects the lungs but may also lead to systemic inflammation with involvement of various other organs [1, 2]. It is mainly transmitted by aerosols and is considered very contagious [3]. The most common symptoms are of respiratory origin and include fever, dry cough, and dyspnea [4]. Since the outbreak in China in December 2019, this SARS-CoV-2 has changed the lives of people around the world and led to the World Health Organization (WHO) declaring a public health emergency [5]. By October 25, 2020 in Germany, a total of 429,181 confirmed cases had been documented by the Robert Koch Institute and 10,032 people had already lost their lives fighting the novel coronavirus [6]. Globally, there were already 42,303,118 confirmed infections and $1,145,695$ deaths [7]. Radiology may contribute significantly to the detection and monitoring of pulmonary manifestations as an adjunct to laboratory testing with RT-PCR (reverse transcriptase polymerase chain reaction). Typical patterns of a COVID-19 infection have been described by various authors, especially on computed tomography (CT) [8-10].

But is it conceivable that an examination method such as chest $\mathrm{X}$-ray that is less complex, less expensive, widely available, and requires short patient contact time could be useful in the diagnostic workup of suspicious cases? With what level of certainty is it able to distinguish a COVID-19 infection from other pneumonias? A chest X-ray that is suspicious for a COVID-19 infection could lead to an earlier isolation of the patient, thus preventing further spreading of the infection, especially if the RT-PCR result is still pending. The aim of this retrospective study is to evaluate certain imaging patterns of a COVID-19 infection of the lungs and help radiologists to identify and highlight these.

\section{Materials and Methods}

This retrospective single-center study was approved by the local ethics committee (BKF Augsburg; ID: BKF2020-28).

\section{Patient collective and two-step analysis}

During the first pandemic period in Germany from February 3 to May 8,2020 , defined as the period from the first to the last confirmed COVID-19 infection at our university hospital, all patients of legal age with respiratory impairment and signs of infection, who presented at the emergency department or were referred to it from external clinics or medical practices and who received an X-ray of the chest on admission, were included in the first step of our analysis. Confirmation was based on serial RT-PCR and may not have been available at the time of the first X-ray on admission as it took 12 to 24 hours for the results of the RT-PCR to be communicated. This cohort comprised 321 patients, with 111 having tested positive for COVID-19.

Besides the type of infection, divided into COVID-19, influenza, and others (not further differentiated common viral and also a very small number of cases of bacterial pneumonia), age and sex were determined for each of these groups. 
In a second step of the analysis, the changes in the radiomorphological pattern on follow-up radiographs throughout the entire course of the hospital stay of all confirmed COVID-19 patients with initially inconspicuous or indeterminate appearance of their chest radiograph were examined to determine whether serial radiographs may confirm typical imaging patterns at a later timepoint of infection and may therefore be helpful.

\section{Chest X-ray}

All thoracic radiographs were digitally recorded and complied with the valid regional regulations for chest $X$-ray examinations. Depending on the clinical condition of the patients, the examination was performed as an anterior-posterior projection at the bedside in a supine position or in an upright standing position in either one plane posterior-anteriorly only or two planes. All follow-up images with relevant morphological changes were included. The interpretation of the chest X-ray examinations was performed by a senior resident and an experienced senior specialist in consensus. In case of disagreements, a third radiologist (senior specialist) was consulted. All readers were blinded to the type of infection of all included patients

The recorded image patterns included the unilateral or bilateral evidence of opacifications and consolidations as well as their predominant position in relation to the hilum as perihilar or peripheral and as located in the upper or lower zone with the hilum as the reference height. In extensive disease, the absence of a clearly predominant distribution either in relation to the hilum or regarding the lower and upper zone could also be rated. The presence of pleural effusions was documented additionally. Based on these findings and in accordance with the study by Wong et al. and the frequently described patterns of findings on $\mathrm{CT}$, the following simplified classification was used to rate the affection of the lung parenchyma with regard to the probability of the presence of a COVID-19 infection [9].

Bilateral and predominantly peripheral opacifications and/or consolidations were rated as typical for a COVID-19 infection.

- Fig. 1-3 show representative images of patients with varying degrees of confirmed COVID-19 infections.

A distribution pattern with opacifications and/or consolidations limited to one pulmonary lobe consistent with lobar pneumonia was rated as non-typical for a COVID-19 infection ( Fig. 4).

All changes that could not be clearly classified as non-typical or typical were rated as indeterminate ( $\vee$ Fig. 5). In a subgroup of these patients with indeterminate findings, soft criteria for a possible COVID-19 infection were defined as the unilateral presence of predominantly peripheral opacifications and/or consolidations with no or only minimal signs of infection on the other side ( $\triangleright$ Fig. 6).

All chest X-ray examinations with no signs of infection were rated as none.

Available radiographic follow-up images were evaluated chronologically. Revision of a previously assigned assessment after inspection of the follow-up examinations was not allowed and the assessment of the follow-up radiographs was also blinded. The aim and ambition of the radiological assessment was not

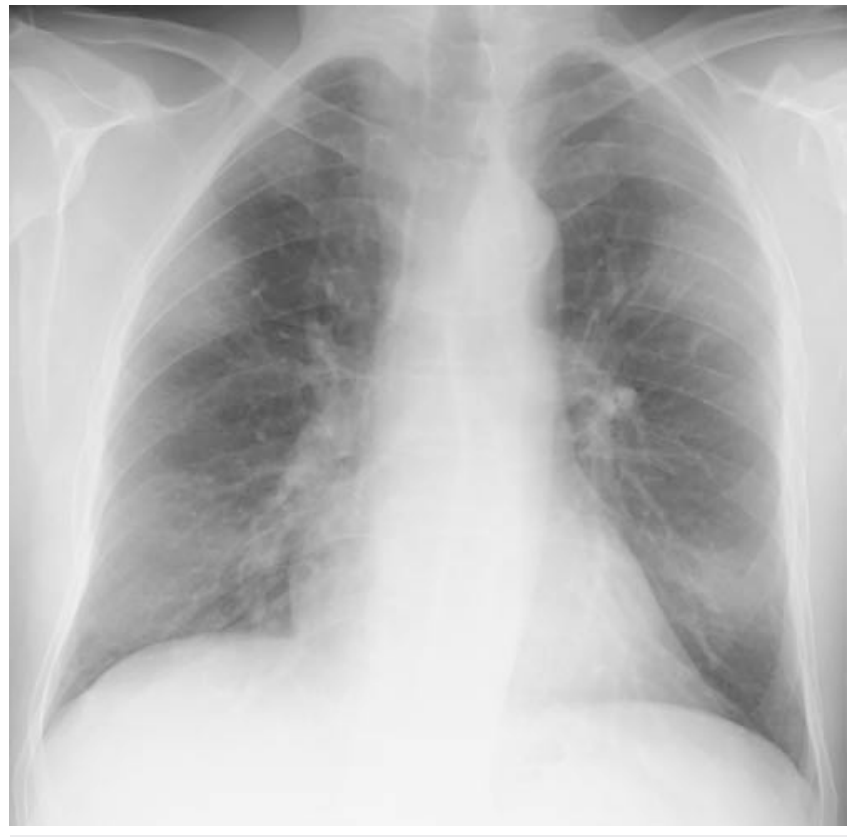

- Fig. 1 Bedside chest radiograph in anterior-posterior projection of a patient with confirmed COVID-19 infection showing typical bilateral and peripherally located opacities.

- Abb. 1 Bettseitige Röntgenaufnahme des Thorax in anteriorposteriorer Projektion eines Patienten mit bestätigter COVID-19Infektion und Nachweis typischer bilateraler und peripher lokalisierter Verschattungen.

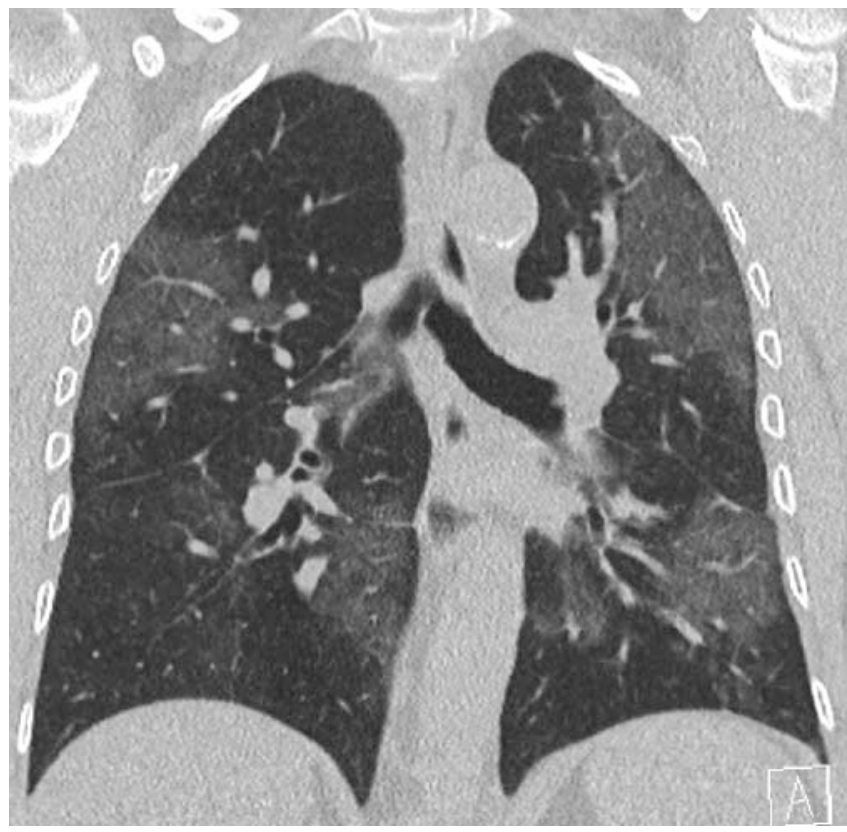

- Fig. 2 Coronary reformation of the chest CT of the same patient as in $\mathbf{F i g .} 1$ showing typical ground glass opacifications in lung peripherals on both sides.

- Abb. 2 Koronare Reformation der CT des Thorax desselben Patienten wie in Abb. 1 mit typischen Milchglastrübungen beidseits in der Lungenperipherie. 


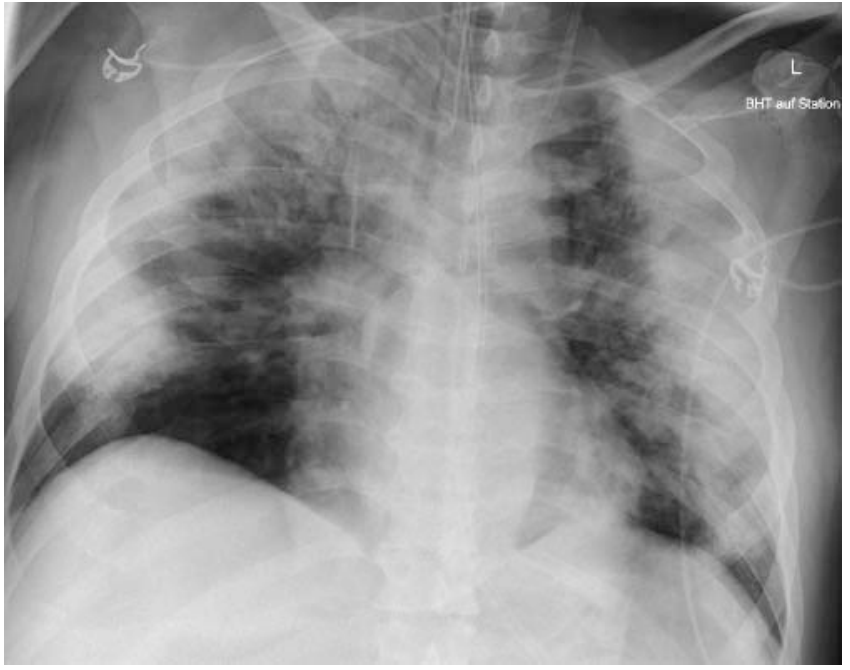

- Fig. 3 Bedside chest radiograph in anterior-posterior projection of a severely affected patient with confirmed COVID-19 infection in the intensive care unit showing typical bilateral and peripheral opacifications and consolidations.

- Abb. 3 Bettseitiges Röntgenbild des Thorax in anterior-posteriorer Projektion eines schwer betroffenen Patienten mit bestätigter COVID-19-Infektion auf der Intensivstation mit typischen bilateralen und peripher lokalisierten Verschattungen und Konsolidierungen.

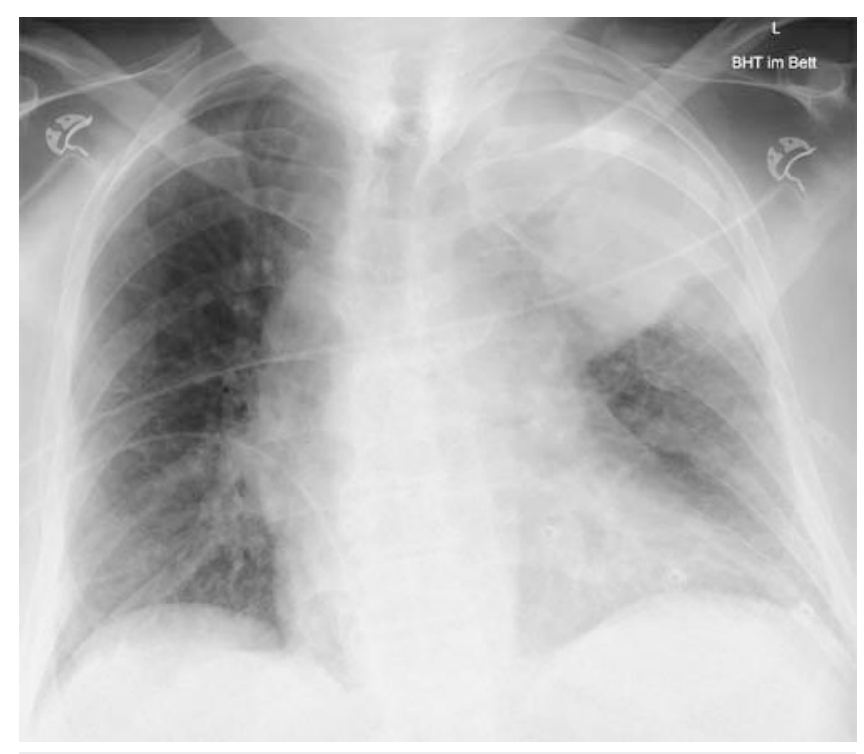

- Fig. 4 Bedside chest radiograph in anterior-posterior projection of a patient with a consolidation of the left upper lobe consistent with clinically confirmed lobar pneumonia.

- Abb. 4 Bettseitiges Röntgenbild des Thorax in anterior-posteriorer Projektion eines Patienten mit Verschattung des linken Oberfeldes, passend zu einer klinisch bestätigten Lobärpneumonie.

to correctly identify as many COVID-19 pneumonias as possible, but to correctly assign the given patterns of findings in order to determine their value.

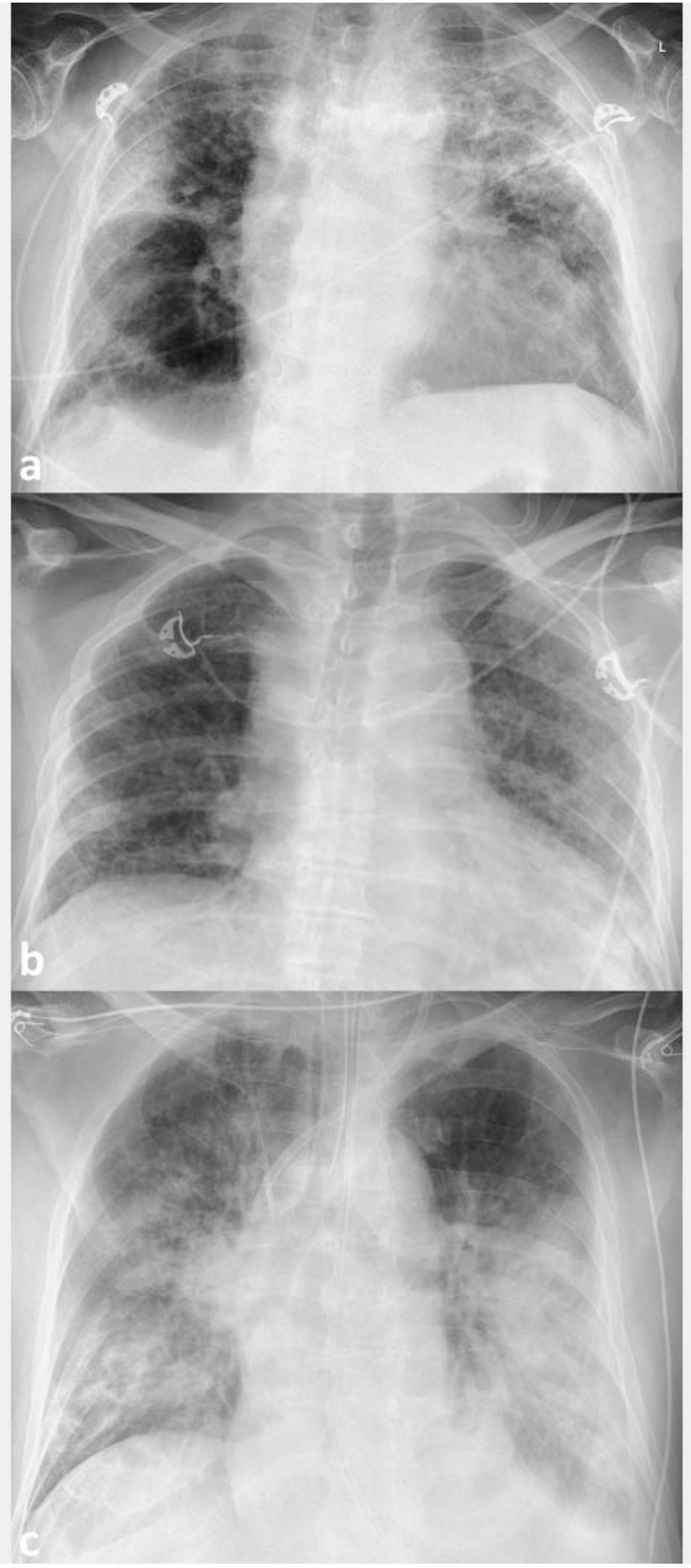

- Fig. 5 Bedside chest radiographs in anterior-posterior projection of three patients with bilateral opacifications classified as indeterminate pattern in confirmed COVID-19 infection a, viral interstitial pneumonia other than COVID-19 and influenza $\mathbf{b}$, and pneumonia associated with confirmed influenza B virus infection c.

- Abb. 5 Bettseitige Röntgenaufnahmen des Thorax in anteriorposteriorer Projektion von 3 Patienten mit als unbestimmt (indeterminate) klassifizierten, bilateralen Verschattungsmustern bei gesicherter COVID-19-Infektion a, sonstiger viraler interstitieller Pneumonie nach Ausschluss einer COVID-19- und Influenza-Infektion b sowie Infiltrate bei gesicherter Pneumonie im Rahmen einer Influenza-B-Infektion c. 


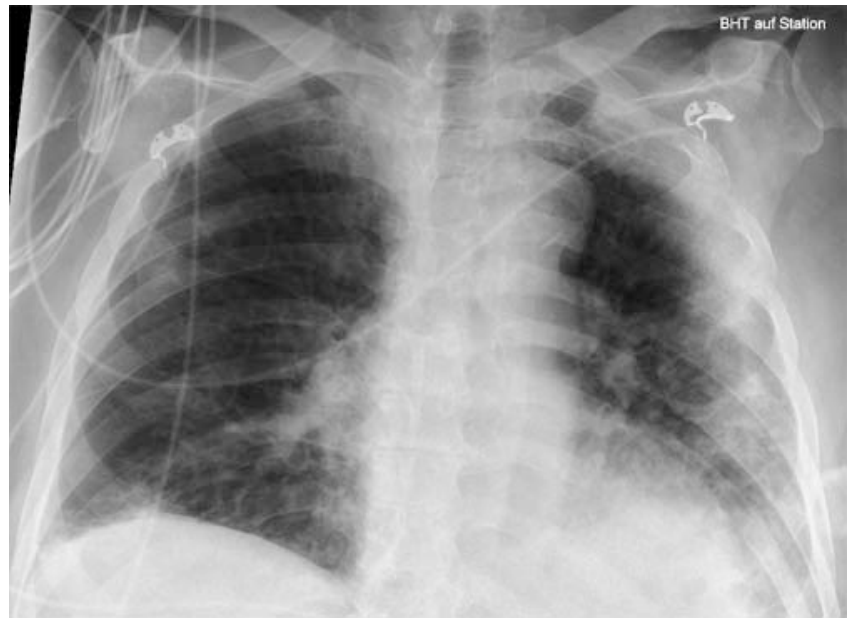

- Fig. 6 Bedside chest radiograph in anterior-posterior projection of a patient with confirmed COVID-19 infection showing typical peripherally located consolidations unilaterally on the left with only minor opacities contralaterally.

Abb. 6 Bettseitige Röntgenaufnahme des Thorax in anteriorposteriorer Projektion eines Patienten mit bestätigter COVID-19Infektion mit typischen peripher lokalisierten Konsolidierungen, jedoch nur einseitig links mit nur dezenten Infiltraten kontralateral.

\section{Laboratory testing}

For the confirmation of a COVID-19 infection, serial oronasal swabs or a bronchoalveolar lavage were performed and examined by RT-PCR. All influenza infections were detected analogously with the corresponding RT-PCR test. Other viral pneumonias, such as respiratory syncytial virus infections, or bacterial pneumonias were not regularly confirmed by laboratory tests.

\section{Statistical analysis}

Statistical analysis was performed using R version 3.6 (https:// www.r-project.org/). Data is shown as median (interquartile range IQR, $25^{\text {th }}-75^{\text {th }}$ percentile). Categorical parameters are shown as quantity and percentage. To assess and compare the diagnostic accuracy of tests, the sensitivity and specificity as well as positive and negative predictive values were calculated, including the corresponding $95 \%$ confidence interval $(\mathrm{Cl})$. To compare categorical variables, the Chi-square test was used. A p-value $\leq 0.05$ was defined as statistically significant.

\section{Results}

\section{Analysis of the chest radiograph on admission}

Between February 3 and May 8, 2020, a total of 321 patients presented at the emergency department with respiratory impairment and signs of infection, underwent chest $X$-ray, and were admitted to one of the COVID-19 wards for further surveillance, diagnostic testing, and therapy. In 111/321 (35\%) of these patients, a COVID-19 infection was confirmed by RT-PCR. Another 22/321 (7\%) patients tested positive for an influenza virus infection. In
- Table 1 Demographic characteristics of the study population during the first pandemic period (IQR: interquartile range).

- Tab.1 Demografische Daten der Studienpopulation während der ersten Pandemiewelle. IQR = interquartile range.

\begin{tabular}{|l|l|l|l|}
\hline & COVID-19 & influenza & other \\
\hline $\mathrm{N}$ & $111 / 321(35 \%)$ & $22 / 321(7 \%)$ & $188 / 321(59 \%)$ \\
\hline $\begin{array}{l}\text { median age } \\
\text { (IQR) [years] }\end{array}$ & $69(54.5-79)$ & $68(50.8-78.8)$ & $75.5(63.5-83)$ \\
\hline $\begin{array}{l}\text { sex } \\
\text { (female/male) } \\
\text { [N] }\end{array}$ & $39 / 72$ & $9 / 13$ & $83 / 105$ \\
\hline
\end{tabular}

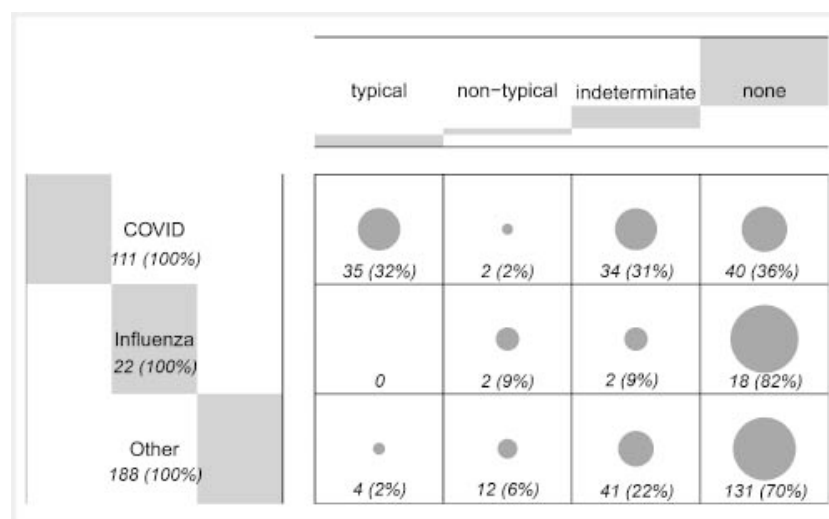

- Fig. 7 Comparative presentation of the relative distribution of the categorized patterns of findings as a balloon plot. The embedded numbers indicate the respective absolute and relative frequencies.

- Abb. 7 Vergleichende Darstellung der relativen Verteilung der kategorisierten Befundmuster als Ballon-Grafik. Die eingebetteten Zahlen geben die absoluten und relativen Häufigkeiten an.

the remaining 188/321 (59\%) patients, neither a COVID-19 nor an influenza virus infection could be detected and a common viral pneumonia or in a very small number of patients a bacterial pneumonia was identified as the cause of the symptoms. The demographic characteristics of the study population are summarized in $>$ Table 1. Initial X-ray examinations were performed as bedside diagnostic testing in 237 cases in a supine position, one in posterior-anterior projection standing upright and 83 times in two planes. The balloon plot in $\mathbf{F i g . ~} 7$ presents the results of the classification of radiomorphological findings on the initial chest radiograph of this collective, with the difference in distribution being highly significant $(p<0.0001)$. The image patterns classified as typical could be detected in almost one third of the COVID-19 patients and, more importantly, in hardly any patient with any other type of pneumonia. Consequently, the diagnostic certainty of the typical pattern of findings can be determined with a sensitivity of $31.5 \%$ (95\% Cl: 22.9-40.2), a very high specificity of $98.1 \%$ (95\% $\mathrm{Cl}$ : 96.2-99.9), and a positive and negative predictive value of 
89.7 \% (95\% Cl: 80.2-99.3) and 73\% (95\% Cl: 67.9-78.2), respectively. 16 patients with confirmed COVID-19 diagnosis and 10 with excluded COVID-19 infection presented with an indeterminate radiomorphological pattern but soft criteria as defined above as the unilateral presence of predominantly peripheral opacifications and/or consolidations with no relevant signs of infection on the contralateral side. When taking these findings into account as typical for a COVID-19 infection, the diagnostic certainty of these patterns results in a sensitivity of $45.9 \%$ (95\% Cl: 36.7-55.2), a still very high specificity of $93.3 \%$ ( $95 \% \mathrm{Cl}$ : 90.0-96.7), and a positive and negative predictive value of $78.5 \%$ (95\% Cl: 68.5-88.5) and $76.6 \%$ (95\% Cl: 71.4-81.8), respectively. Another important aspect that supports diagnostic certainty is the fact that the patterns of findings defined as non-typical, which rather suggest bacterial pneumonia, hardly interfere with the image patterns of a COVID-19 infection.

Pleural effusion was found in only $4 / 111$ (4\%) patients with confirmed COVID-19 infection, in 2/22 (9\%) patients with influenza virus infection, and in $37 / 188$ (19\%) patients with other types of pneumonia. The difference between COVID-19 patients and those with other pneumonias was highly significant $(p<0.0001)$.

\section{Analysis of the follow-up radiographs in COVID-19}

27 /74 (36\%) COVID-19 patients with initially no or indeterminate imaging findings received at least one follow-up chest radiograph. In the remaining patients, there was no indication for re-imaging due to their clinical improvement and timely discharge. Among those 27 patients with follow-up imaging, only 4 (15\%) presented with imaging characteristics now defined as typical for a COVID-19 infection 4 to 9 days after the initial radiograph.

\section{Discussion}

Since February 2020, the great majority of imaging studies on pulmonary involvement in patients with confirmed COVID-19 infection dealt with chest CT [10]. Only a few publications referred to a possible role of chest X-ray $[9,11]$. The reasons for this seem obvious. Computed tomography provides a more detailed and non-superimposed view of the lung parenchyma and is able to detect subtle interstitial changes much earlier than a plain radiograph, probably even only performed as bedside imaging in anterior-posterior projection. However, despite some studies having shown overwhelmingly high confidence in diagnosing a COVID-19 infection, CT is still not recommended as a screening method for good reason. The published sensitivity of CT ranges from $61 \%$ to $99 \%$ and the specificity from $24 \%$ to $94 \%$ [12-18]. These wide ranges in diagnostic certainty can be explained by case selection, especially in the early studies. The observation of only a small number of severely ill and known positive persons represents a decisive bias. However, if asymptomatic patients are also included, the detection rate drops noticeably [13]. The even greater range in the reported specificity is probably caused by the significant overlap of imaging findings with other viral pneumonias. In regions with a low prevalence of COVID-19 infection, this may lead to a higher number of false-positive diagnoses of COVID-19 infections by CT. However, studies showed that the application of dedicated reporting stand- ards, like COVID-RADS, or even the use of artificial intelligence may improve diagnostic performance and reliability [19-21]. Nevertheless, CT is expensive and not available to such an extent that it can be a useful screening method compared to swab tests and RT-PCR with the increasing numbers of cases.

An imaging method that has received little attention so far and is not subject to these restrictions is plain chest $X$-ray. The first group to present a comprehensive analysis of chest radiographic findings in 64 COVID-19 patients was Wong et al., who demonstrated a sensitivity of $69 \%$, which was lower than RT-PCR but still impressive [9]. Since only COVID-19 patients were studied, no statement could be made about the specificity of the observed changes. In our analysis, we wanted to avoid this weakness seen in many studies and included all patients who presented with dyspnea and signs of infection between the detection of the first and last COVID-19 infection during the first wave of the pandemic in our clinic. By looking at the initial X-ray image on admission and by blinding the readers to the RT-PCR result, a screening situation was simulated which should realistically reflect the diagnostic value of chest $X$-ray. Therefore, we are confident that the reported sensitivity of up to $45.9 \%$, specificity of up to $98.1 \%$, and negative predictive value of $76.6 \%$ are realistically achievable. However, these figures are only meaningful in the case of a pandemic wave with a correspondingly high prevalence and must under no circumstances be generalized to periods with a very low prevalence. For this, larger case series would have to be systematically investigated. Knowledge of the typical patterns of findings and a standardized classification to communicate results in time are crucial. The acquisition and interpretation of an X-ray image usually takes no more than half an hour and can therefore support the triage of patients within a very short time, while waiting for the results of the RT-PCR. It takes 12-24 hours to receive the results of regular tests and even rapid tests realistically require two to four hours until the result is communicated. Particularly for countries with less efficient health care systems and corresponding resources or even a lack of testing capacities, there is quite relevant potential in thoracic X-ray examinations. However, our results cannot be easily transferred and would have to be scientifically assessed again in a respective context.

Imaging patterns defined as non-typical for a COVID-19 infection on chest X-ray can almost certainly exclude a SARS-CoV-2 infection and be attributed to a lobar pneumonia. However, it should be mentioned that only $5 \%$ of all evaluated cases were assigned to this category. Especially the large number of images taken in anterior-posterior projection due to the patients' state of health and the lack of a lateral view may affect diagnostic certainty. However, clear lobar pathologies should be distinguishable.

Regarding viral pneumonia, it should be noted that although there appear to be clear differences in their patterns, a complete and reliable differentiation of the various viral pneumonias cannot be made with absolute certainty $[22,23]$, neither with a chest radiograph nor with $\mathrm{CT}$. Differentiation of other viral pneumonias was and is not of current interest. Rather the aim of the current study was the differentiation from COVID-19 and is the reason not to make further subgroups like for respiratory syncytial virus infections. 
However, since the imaging patterns described for COVID-19 also apply to patterns caused by other coronaviruses like SARS$\mathrm{COV}$ and MERS-CoV, a distinction with respect to these may be more difficult to make and further studies would be necessary to clarify this question $[24,25]$. However, it seems unlikely that this discrimination is of any relevance in the current pandemic.

In our collective, serial follow-up radiographs did not seem to add relevant information. It took several days for typical changes to occur in a minority of patients. However, this is of limited value in that the severity of the symptoms and the time of onset of the first symptoms were not included in the analysis.

\section{Limitations}

The presented study has certain methodological limitations. Unfortunately, in the retrospective evaluation, many clinical data, like symptom onset and severity, were not documented with sufficient accuracy and traceability and were therefore not available in a usable form. The inclusion of the X-rays of all patients with respiratory symptoms at the time of the first wave of the pandemic at the time of first contact in the emergency room ensured that a realistic scenario that could reoccur in a comparable form could be considered. It is unlikely that a majority of patients will now, during the second wave, present at a completely different stage of disease, which is currently becoming apparent with the number of cases already rising again. This, however, reveals another limitation as the presented results only apply to periods with a comparably high prevalence of COVID-19 infections. The diagnostic certainty of the first swab test at the time of admission was also not taken into account. Finally, all patients tested positive for SARS-CoV-2 in the early stages of their stay by serial tests. This was the only important information with regard to the defined purpose of our study. Comparison with the sensitivity of RT-PCR influenced by many possible confounders did not seem relevant to us.

\section{Conclusion}

During the first wave of the pandemic, with a correspondingly high prevalence of patients with COVID-19 pneumonia, chest radiographs showed only low to moderate sensitivity. However, with regard to the frequently described typical pattern of findings, the specificity was surprisingly high. Peripheral opacities and/or consolidations with a bilateral or unilateral location with no or only marginal signs of inflammation contralaterally are highly suspicious for a COVID-19 infection. As chest radiographs are available more frequently and often earlier than chest CT and are usually also available more quickly than the results of the swab test, there is considerable potential to usefully include this additional information in the early triaging of patients in the case of a rising number of cases.

\section{Conflict of Interest}

The authors declare that they have no conflict of interest.

\section{References}

[1] Zhu N, Zhang D, Wang W et al. A novel coronavirus from patients with pneumonia in China, 2019. New England Journal of Medicine 2020. doi:10.1056/NEJMoa2001017

[2] Guzik T], Mohiddin SA, Dimarco A et al. COVID-19 and the cardiovascular system: implications for risk assessment, diagnosis, and treatment options. Cardiovascular research 2020. doi:10.1093/cvr/cvaa106

[3] Zhang H, Liao Y-S, Gong J et al. Clinical characteristics of Coronavirus Disease (COVID-19) patients with gastrointestinal symptoms: A report of 164 cases. Digestive and Liver Disease 2020. doi:10.1016/j. dld.2020.04.034

[4] Wang D, Hu B, Hu C et al. Clinical characteristics of 138 hospitalized patients with 2019 novel coronavirus-infected pneumonia in Wuhan, China. Jama 2020; 323: 1061-1069. doi:10.1001/jama.2020.1585

[5] World Health Organisation. Novel Coronavirus(2019-nCoV) Situation Report - 11.2020. In 2020 September 16.

[6] Robert-Koch-Institut. COVID-19: Fallzahlen in Deutschland und weltweit. In 2020 October 25.

[7] World Health Organisation. WHO Coronavirus Disease (COVID-19) Dashboard. In 2020 October 25.

[8] Wang Y, Dong C, Hu Y et al. Temporal changes of CT findings in 90 patients with COVID-19 pneumonia: a longitudinal study. Radiology 2020. doi:10.1148/radiol.2020200843

[9] Wong HYF, Lam HYS, Fong AH-T et al. Frequency and distribution of chest radiographic findings in COVID-19 positive patients. Radiology 2020. doi:10.1148/radiol.2020201160

[10] Pontone G, Scafuri S, Mancini ME et al. Role of computed tomography in COVID-19. Journal of cardiovascular computed tomography 2020. doi:10.1016/j.jcct.2020.08.013

[11] Cozzi D, Albanesi M, Cavigli E et al. Chest X-ray in new Coronavirus Disease 2019 (COVID-19) infection: findings and correlation with clinical outcome. La Radiologia medica 2020. doi:10.1007/s11547-020-01232-9

[12] Ai T, Yang Z, Hou H et al. Correlation of chest CT and RT-PCR testing in coronavirus disease 2019 (COVID-19) in China: a report of 1014 cases. Radiology 2020. doi:10.1148/radiol.2020200642

[13] Dalglish SL. COVID-19 gives the lie to global health expertise. The Lancet 2020; 395: 1189. doi:10.1148/ryct.2020200110

[14] Dangis A, Gieraerts C, Bruecker YD et al. Accuracy and reproducibility of low-dose submillisievert chest CT for the diagnosis of COVID-19. Radiology: Cardiothoracic Imaging 2020; 2: e200196. doi:10.1148/ ryct.2020200196

[15] Fang Y, Zhang H, Xie J et al. Sensitivity of chest CT for COVID-19: comparison to RT-PCR. Radiology 2020. doi:10.1148/radiol.2020200432

[16] Damiano C, Michela P, Francesco P et al. Chest CT features of COVID-19 in Rome, Italy. Radiology 2020. doi:10.1148/radiol.2020201237

[17] Bai HX, Hsieh B, Xiong Z et al. Performance of radiologists in differentiating COVID-19 from viral pneumonia on chest CT. Radiology 2020. doi:10.1148/radiol.2020200823

[18] Kim H, Hong H, Yoon SH. Diagnostic performance of CT and reverse transcriptase-polymerase chain reaction for coronavirus disease 2019: a meta-analysis. Radiology 2020. doi:10.1148/radiol.2020201343

[19] Salehi S, Abedi A, Balakrishnan S et al. Coronavirus disease 2019 (COVID-19): a systematic review of imaging findings in 919 patients. American Journal of Roentgenology 2020. doi:10.1007/s00330-02006863-0

[20] Bai HX, Wang R, Xiong Z et al. Al augmentation of radiologist performance in distinguishing COVID-19 from pneumonia of other etiology on chest CT. Radiology 2020. doi:10.1148/radiol.2020201491 
[21] Li L, Qin L, Xu Z et al. Artificial intelligence distinguishes COVID-19 from community acquired pneumonia on chest CT. Radiology 2020. doi:10.1148/radiol.2020200905

[22] Koo HJ, Lim S, Choe J et al. Radiographic and CT features of viral pneumonia. Radiographics 2018; 38: 719-739. doi:10.1148/rg.2018170048

[23] Vogel-Claussen J, Ley-Zaporozhan J, Agarwal P et al. Empfehlungen der AG Thoraxdiagnostik der Deutschen Röntgengesellschaft zur klinischen Anwendung der Thoraxbildgebung und strukturierten CT-Befundung bei COVID-19-Pandemie. RoFo: Fortschritte auf dem Gebiete der Rontgenstrahlen und der Nuklearmedizin 2020. doi:10.1055/a-1174-8378

[24] Nicolaou S, Al-Nakshabandi NA, Müller NL. SARS: imaging of severe acute respiratory syndrome. American Journal of Roentgenology 2003; 180: 1247-1249. doi:10.2214/ajr.180.5.1801247

[25] Das KM, Lee EY, Jawder SEA et al. Acute Middle East respiratory syndrome coronavirus: temporal lung changes observed on the chest radiographs of 55 patients. American Journal of Roentgenology 2015; 205: W267-S274. doi:10.2214/ajr.15.14445 